\title{
Technology Enhanced Learning for People with Intellectual Disabilities and Cerebral Paralysis: The MAS Platform
}

\author{
Ricardo Colomo-Palacios, Fernando Paniagua-Martín, \\ Ángel García-Crespo, and Belén Ruiz-Mezcua \\ Universidad Carlos III de Madrid, Computer Science Department \\ Av. Universidad 30, Leganés, 28911, Madrid, Spain \\ \{ricardo.colomo, fernando.paniagua, angel.garcia, belen.ruiz\}@uc3m.es
}

\begin{abstract}
Education for students with disabilities now takes place in a wide range of settings, thus, including a wider range of assistive tools. As a result of this, one of the most interesting application domains of technology enhanced learning is related to the adoption of learning technologies and designs for people with disabilities. Following this unstoppable trend, this paper presents MAS, a software platform aimed to help people with severe intellectual disabilities and cerebral paralysis in their learning processes. MAS, as a technology enhanced learning platform, provides several tools that supports learning and monitoring for people with special needs, including adaptative games, data processing and monitoring tools. Installed in a special needs education institution in Madrid, Spain, MAS provides special educators with a tool that improved students education processes.
\end{abstract}

Keywords: assistive technology, adaptive toys, handicapped persons, special needs, assistive technologies.

\section{Introduction}

Training and support methods for people with intellectual disabilities are generally very staff intensive and thus quite expensive to the supporting agency [1]. Providing quality educational programs to students with profound disabilities presents a tremendous challenge [2]. Computer technology offers promising new approaches to reducing the dependence of people with mental retardation on others [1]. Though studies reveal [3] that it is how teachers adapt and utilize the technology that makes a difference and not the technology itself, technology offers new horizons for both educators and learners.

Several studies (e.g. [4], [5]) reveal that students with serious developmental disabilities frequently fail to develop speech and language skills. Assistive technology, including switches, alternative and augmentative communication (AAC) devices, and environmental controls, provides an alternative means for students to access their environments, exert control, express themselves, and learn simple tasks [6]. AAC 
refers to a compilation of methods and technology designed to supplement spoken communication for people with limited speech or language skills [7].

In the field of technology, some studies have indicated that children with developmental disabilities can learn pointing [8], [9]. However, people with severe disabilities generally have important difficulties to work with mouse devices [10]. Sometimes, special education teachers have difficulties to teach using mouses [11]. New tools need to be applied in such cases: assistive technology. It is proved that providing a variety of stimuli has been identified as a key component in teaching switch technology [12]. However, limited budgets may restrict the purchase of several reinforcing devices [13]. On the other hand, according to [1] one of the greatest advantages of using computer technology and multimedia for training is the ability to customize the training to meet the needs of the person.

A variety of commercially developed computer software programs are available to teach cause and effect via a single switch and switch interface [13]. The challenge to provide novelty is further compounded when children with severe and profound disabilities exhibit little or no interest in commercially available toys [13].

This paper describes MAS, a software system to reinforce the learning process of people with cerebral palsy and cognitive disabilities through the use of interactive games and diverse devices in one unique solution. MAS is easy to use for both end users and intermediate users, is highly configurable and contemplates and provides tools to deal with some of the disabilities that, additionally, this group of people has usually, as coordination and movement difficulty, visual and hearing impairments. MAS is based in the fact reported by several authors (e.g [14], [15]) that effective reinforcers must be presented to the student in order to attract him or her to the tool. In order to do so, MAS is designed to fully configurable in its games, being able to include particularized multimedia clips or photos for each student.

The remainder of the paper is organized as follows. Section 2 outlines relevant literature in the area about the field of study. In Section 3, the architecture for the MAS approach is presented along with the description of the implementation of the architecture. Conclusions and future work are discussed in Section 4.

\section{Background}

Computer technology offers promising new approaches to reducing the dependence and improve the development of people with disabilities [1]. Siegel [16] pointed out that technology would not cure intellectual disability or even fully compensate for the difficulties encountered by persons with intellectual disabilities, but, information and communication technology can, however, improve their abilities to better integrate, changing also the way they learn [17], and improving the lives of persons with disabilities [18] and facilitating participation in society [19].

According to [20], assistive technology devices to aid persons with disabilities can be technological (vibrating pager, Palmtop, PC) or nontechnological (picture prompts, activity schedules). Focusing on technological devices, Briant and Briant [21] pointed out that "For people without disabilities, technology makes things easier, for people with disabilities technology makes things possible". 
Due the importance of assistive technology for people with disabilities, this research area has been summarized in many works. In [22] there is a review of the relevant literature regarding assistive technology as an instructional tool to assist college students with language disabilities, in [13] authors complete a literature review in the field of daily tasks, [3] provides an updated list of various types of assistive technology is provided of different kind of disabilities, and [23] presents a U.S. national survey of the use of assistive technology by adults with mental retardation.

There are several cases of successful use of assistive technology in children and teenagers education in fields like: Dyslexia [24], Autism [25] or Visual Impairments [26] to cite but a few. Finally, in the field of people with intellectual disabilities, there are various works that deals with technologies such as palmtop computers [27], [28], video technologies [29], [30] or high-tech AAC (see [7] for a full and recent review), to cite the more relevant ones.

MAS, following the philosophy of an adaptative toy, it is designed to be an assistive technology that supports the development of people with intellectual disabilities and cerebral paralysis.

\section{MAS: Technology Enhanced Learning for Children with Severe Intellectual Disabilities and Cerebral Paralysis}

There are many educational support software tools designed for young adults and children. However, these systems are in many cases difficult to use for children with intellectual disabilities, who, in many cases present also other kind of disabilities: impaired vision, hearing disabilities, etc. Moreover, each of these children presents one or many disabilities at specific grade levels. In this scenario, commercial software that is usually based on generalization is not a valid approach for people with disabilities that need fully configurable platforms, able to be adapted to their particular needs. MAS is a platform designed to support educational activities with a special target: people with intellectual disabilities and cerebral paralysis.

\subsection{Overview Architecture}

MAS is designed as an aggregation of three main modules as depicted in Figure 1. These modules are: user management module, that allows to do the maintenance of users and their disabilities; games management module, that allow maintenance games (create, configure, personalize); and games zone, the module that allow play games and perform activities.

Through User Management module, administrators can define and maintain particularities about students. This allows administrators to define disabilities, grades of disabilities and displays and inputs applicable (sweeps) for a given user. The final aim is to define the set of games and aids to be configured for the user.

Games management module is the one responsible of the matching between children needs and activities available. This feature is very important since some people with cerebral paralysis have difficulty to recognize pictures or photographs, and they need specific images to interact with the application. Educators must be aware that certain users can get a fright if listen certain sounds and to prevent this, using this 


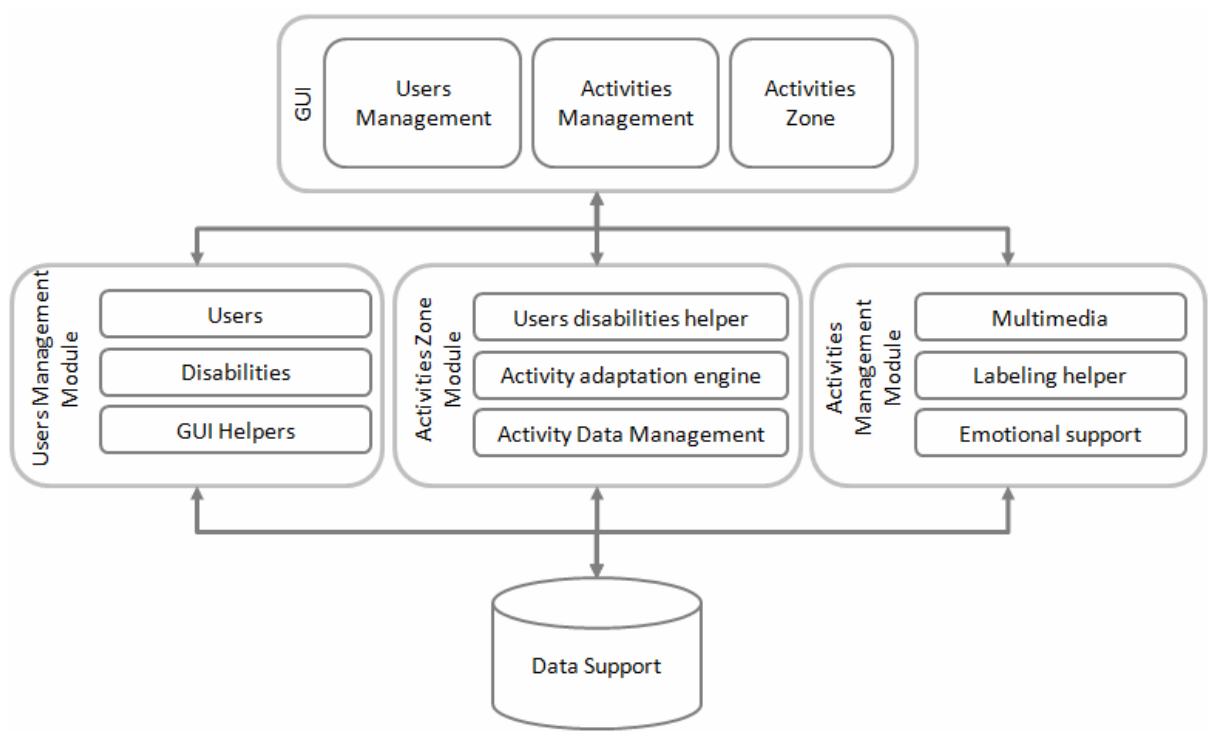

Fig. 1. MAS Architecture

module is crucial to adapt the stimulus to users. Using this module, educators can adapt images, videos and sounds to children's activities in a fully configurable way.

Games zone is the one dedicated to play games. These games will be shown adapted to user's disabilities in order to let user interact with the game using specific inputs. Thus, this module reads personal configuration set up to provide the specific version of each game, bearing in mind user's disabilities, and specifics multimedia resources. This module is designed to serve also as a learning support system. To do so, the system automatically stores the time consumed by the user, the number of right and wrong answers, timestamp, the user, and many other data. This is a very important feature because it allows instructors check users' progress.

\subsection{Implementation Issues}

The implementation of the architecture as a whole has been based on Microsoft .NET Framework 3.5 SP1 using C\#. Microsoft .NET provides a framework in which designing easy to use graphic user interfaces can be done in a quick and efficient way, and also a possibility to include eXtensible Application Markup Language (XAML) XML-based interface definitions for Windows Presentation Foundation (WPF) applications.

For the liaison between the business logical and the presentation layer, it is based on the Model-View-Controller design pattern, where the GUI layer corresponds with the view, the business logic layer corresponds with the controller, and the persistence layer corresponds with the model. The proof of the concept implementation includes Microsoft Access as desktop database management system. 


\subsection{Games}

MAS prototype is able to deal with four kind of games:

- Cause-effect games: This kind of games presents an initial window displaying a video, playing an audio file, or showing an image. This multimedia resource will remain in the window until the user press mouse button (or performs a similar action via any equivalent device). When the system detects the action, a new window will be shown presenting other multimedia resource and waits until user performs new action.

- Sequence of images games. In this case, a sequence of images, videos or sounds is presented. This sequence helps users to get familiar with the elements that can be found in other games. There are two possibilities of interaction with the user: automatic transitions and transitions driven by user interaction.

- Image selection games: This kind of games is based in test games. Administrator writes questions using images, sounds and videos. Once the question is presented, user selects one or more images from a list: at least one of them is correct. If the user's response is correct, then he or she will receive reward, in the form of a video, audio or image.

- $\quad$ Ordering games: These games are based on questions, but in this case, the task is to arrange answers following a given criteria. One more time, if user's answers are correct, then user gets a prize, in the form of a video, audio or image.

It's important to point out that, due to the design of MAS, this tool can support new games and artifacts by configuration, without issuing a new version of the tool.

\section{Conclusions and Future Work}

In this paper MAS, a fully customizable platform to support the development of people with intellectual disabilities is presented. MAS is based on the use adaptive games and effective reinforcers (photos, multimedia clips, sounds, etc) to attract the student to the tool. The feedback of its implementation gives promising results. MAS was installed in a special needs education institution in Madrid, Spain, MAS provides special educators with a tool that, according to their comments and feedback, improved students education processes.

Future works should be centered on extending MAS to the internet. Although the design of specific tools for the internet is still a challenge, this global network brings also opportunities to MAS. This new feature will bring the possibility to collect information from all over the world, bringing also the chance to compare results, learning processes, teaching styles and cultural differences.

\section{References}

1. Davies, D.K., Stock, S.E., Wehmeyer, M.L.: Enhancing Independent Task Performance for Individuals with Mental Retardation Through Use of a Handheld Self-Directed Visual and Audio Prompting System. Education and Training in Mental Retardation and Developmental Disabilities 37(2), 209-218 (2007) 
2. Smith, P.D., Gast, D.L., Logan, K.R., Jacobs, H.A.: Customizing instruction to maximize functional outcomes for students with profound multiple disabilities. Exceptionality 9(3), 135-145 (2001)

3. Sze, S., Murphy, J., Smith, M., Yu, S., Murphy, J.: An investigation of various types of assistive technology (AT) for students with disabilities. In: Proceedings of Society for Information Technology and Teacher Education International Conference, vol. 2004(1), pp. 4459-4964. AACE, Norfolk (2004)

4. Sturm, J.M., Clendon, S.A.: Augmentative and alternative communication, language, and literacy: Fostering the relationship. Topics in Language Disorders 24(1), 76-91 (2004)

5. Hetzroni, O.E.: A positive behavior support: A preliminary evaluation of a school-wide plan for implementing AAC in a school for students with intellectual disabilities. Journal of Intellectual and Developmental Disabilities 28(3), 283-296 (2003)

6. Cook, A.M., Hussey, S.M.: Assistive technologies: Principles and practice, 2nd edn. Mosby, St. Louis (2002)

7. Wilkinson, K.M., Hennig, S.: The state of research and practice in augmentative and alternative communication for children with developmental/intellectual disabilities. Developmental disabilities research reviews 13(1), 58-69 (2007)

8. Durfee, J.L., Billingsley, F.F.: A comparison of two computer input devices for uppercase letter matching. American Journal of Occupational Therapy 53(2), 214-220 (1999)

9. Shimizu, H., McDonough, C.S.: Programmed instruction to teach pointing with a computer mouse in preschoolers with developmental disabilities. Research in Developmental Disabilities 27(2), 175-189 (2006)

10. Rao, R.S., Seliktar, R., Rahman, T.: Evaluation of an isometric and a position joystick in a target acquisition task for individuals with cerebral palsy. IEEE Transactions on Rehabilitation Engineering 8(1), 118-125 (2000)

11. Shih, C.H., Shih, T.S.: Assisting people with multiple disabilities to use computers with multiple mice. Research in Developmental Disabilities 30(4), 746-754 (2009)

12. Daniels, L.E., Sparling, J.W., Reilly, M., Humphry, R.: Use of assistive technology with young children with severe and profound disabilities. Infant-Toddler Intervention: The Transdisciplinary Journal 5(1), 91-111 (2005)

13. Mechling, L.C.: Assistive Technology as a Self-Management Tool for Prompting Students with Intellectual Disabilities to Initiate and Complete Daily Tasks: A Literature Review. Education and Training in Developmental Disabilities 42(3), 252-269 (2007)

14. Lancioni, G.E., O'Reilly, M.F., Basili, G.: Use of microswitches and speech output systems with people with severe/profound intellectual or multiple disabilities: A literature review. Research in Developmental Disabilities 22(1), 21-40 (2001)

15. Logan, K.R., Gast, D.L.: Conducting preference assessments and reinforcer testing for individuals with profound multiple disabilities: Issues and procedures. Exceptionality 9(3), 123-134 (2001)

16. Siegel, J.: Utilizing Technology for the Inclusion of Individuals with Mental Retardation. In: Retish, P., Reiter, S., et al. (eds.) Adults with Disabilities: International Perspectives in the Community, pp. 287-308. Lawerence Erlbaum Associates, Inc., Mahwah (1999)

17. Li-Tsang, C.W.P., Chan, C.C.H., Lam, C., Hui-Chan, C., Yeung, S.Z.: Evaluations of an Information and Communication Technology (ICT) Training Programme for Persons with Intellectual Disabilities. In: Miesenberger, K., Klaus, J., Zagler, W.L., Burger, D. (eds.) ICCHP 2004. LNCS, vol. 3118, pp. 1032-1038. Springer, Heidelberg (2004)

18. Wehmeyer, M.L.: Assistive technology and students with mental retardation: Utilization and barriers. Journal of Special Education Technology 14(1), 48-58 (1999) 
19. Parette, H.P.: The importance of technology in the education and training of persons with mental retardation. Education and Training in Mental Retardation 26(2), 65-178 (1991)

20. Bryant, D.P., Bryant, B.R., Raskind, M.H.: Using assistive technology to enhance the skills of students with learning disabilities. Intervention in School and Clinic 34(1), 53-58 (1998)

21. Bryant, D.P., Bryant, B.R.: Assistive technology for people with disabilities. Allyn and Bacon, Boston (2002)

22. Martínez-Marrero, I., Estrada-Hernández, N.: Assistive Technology: An Instructional Tool to Assist College Students with Written Language Disabilities. TechTrends 52(1), 56-62 (2008)

23. Wehmeyer, M.L.: National Survey of the Use of Assistive Technology by Adults with Mental Retardation. Mental Retardation 36(1), 44-51 (1998)

24. Draffan, E.A., Evans, D.G., Blenkhorn, P.: Use of assistive technology by students with dyslexia in post-secondary education. Disability and Rehabilitation: Assistive Technology 2(2), 105-116 (2007)

25. Hess, K.L., Morrier, M.J., Heflin, J., Ivey, M.L.: Autism Treatment Survey: Services Received by Children with Autism Spectrum Disorders in Public School Classrooms. Journal of Autism and Developmental Disorders 38(5), 961-971 (2007)

26. Johnstone, C., Thurlow, M., Altman, J., Timmons, J., Kato, K.: Assistive Technology Approaches for Large-Scale Assessment: Perceptions of Teachers of Students with Visual Impairments. Exceptionality: A Special Education Journal 17(2), 66-75 (2009)

27. Riffel, L.A., Wehmeyer, M.L., Turnbull, A.P., Lattimore, J., Davies, D., Stock, S., Fisher, S.: Promoting independent performance of transition-related tasks using a palmtop PCbased self-directed visual and auditory prompting system. Journal of Special Education Technology 20(2), 5-14 (2005)

28. Stock, S.E., Davies, D.K., Davies, K.R., Wehmeyer, M.L.: Evaluation of an Application for Making Palmtop Computers Accessible to Individuals with Intellectual Disabilities. Journal of Intellectual and Developmental Disability 31(1), 39-46 (2006)

29. Mechling, L.C., Gast, D.L., Cronin, B.A.: The effects of presenting high preference items, paired with choice, via computer-based video programming on task completion of students with a diagnosis of autism spectrum disorder. Focus on Autism and Other Developmental Disabilities 21(1), 7-13 (2006)

30. Mechling, L.C., Pridgen, L., Cronin, B.A.: Computer-based video instruction to teach students with intellectual disabilities to verbally respond to questions and make purchases in fast food restaurants. Education and Training in Developmental Disabilities 40(1), 47-59 (2005) 